\title{
A rare cause of acute abdomen: Splenic hematoma and rupture resulting from pancreatitis
}

\author{
Fevzi Cengiz, Savaș Yakan, İlhan Enver
}

ABSTRACT

Clinic of $1^{\text {st }}$ General Surgery, İzmir Bozyaka Training Hospital, İzmir, Turkey

This case was presented as a poster presentation $(\mathrm{Pb}-48)$ at the $18^{\text {th }}$ National Surgery Congress, 23-27 May 2012, İzmir, Turkey.

\section{Address for Correspondence Dr. Fevzi Cengiz \\ Clinic of $1^{\text {st }}$ General Surgery, İzmir Bozyaka Training Hospital, İzmir, Turkey \\ Phone.: +905053573124 \\ e-mail: drfevzi@gmail.com}

Received: 17.07 .2012

Accepted: 29.07.2012

Online Available Date: 28.05 .2013

(C) Copyright 2013 by Turkish Surgical Association

Available online at www.ulusalcerrahidergisi.org
Splenic subcapsular hematoma and splenic rupture due to pancreatitis are rare causes of acute abdomen. Here we report a case of splenic hematoma and rupture resulting from a second attack of pancreatitis in a 38 year-old woman with chronic pancreatitis due to alcoholism. Her first pancreatitis attack, 4 months before the second, was complicated with a pancreatic pseudocyst that was drained and acute renal failure. The patient underwent pancreatic necrosectomy and splenectomy, and was discharged on the sixth postoperative day without any further complication. We conclude that splenic hematoma, a complication of pancreatitis attack, which may require emergency surgical intervention, must be kept in mind in order to make an early diagnosis. Considering a possible subsequent attack of pancreatitis and determining follow-up criteria, radical treatment must be planned immediately.

Key Words: Subcapsular splenic hematoma, splenic rupture, pancreatitis, pancreatic pseudocyst

\section{INTRODUCTION}

Despite the close proximity of the pancreas to the spleen, splenic complications in chronic pancreatitis are rare, with less than $5 \%$ of patients requiring surgery for splenic complications (1). How and when this complication occurs and how it should be treated is not clearly stated in the literature. In this article, a pancreatic pseudocyst, treated previously with percutaneous drainage and followed by a second attack of pancreatitis that required an emergency operation due to splenic hematoma and rupture, eventually causing acute abdomen, is presented and the literature is discussed.

\section{CASE PRESENTATION}

Thirty-eight-year-old woman was referred to the emergency room with complaints of abdominal pain, nausea, and vomiting. She had a history of chronic alcohol consumption and an attack of acute pancreatitis with acute renal failure 4 months ago. Her abdominal ultrasonography and computed tomography at that time showed a pancreatic pseudocyst, $10 \times 5 \mathrm{~cm}$ in size, which was percutaneously drained by interventional radiology. Approximately $175 c c$ purulent material was drained with no identification on microbiological culture. She was discharged after improvement of her clinical condition without the need for dialysis.

In the intervening period, the patient was asymptomatic and did not comply with her scheduled followups. The patient had no history of trauma. In the emergency department examination, she had tachycardia $(120 / \mathrm{min})$, hypotension $(70 / 50 \mathrm{mmHg})$, abdominal distension and tenderness in all quadrants. Her laboratory findings showed; C- reactive protein (CRP); $30.5 \mathrm{mg} / \mathrm{dL}$, hemoglobin $(\mathrm{Hb}) 6.6 \mathrm{~mm}^{3}$, leukocyte count and amylase $17300 / \mathrm{mm}^{3} 323 \mathrm{U} / \mathrm{L}$. Aspartate transaminase (AST) and alanine aminotransferase (ALT) levels and coagulation tests were within normal limits. On ultrasonography free fluid was seen in the perihepatic, perisplenic area, Morrison and pouch of Douglas with a $120 \mathrm{~mm}$ diameter heterogeneous lesion, containing solid and cystic areas. Abdominal CT revealed cystic structures located at the junction of tail and body of the pancreas, the biggest one $6 \mathrm{~cm}$ in diameter and heterogeneous fluid collection within the splenic capsule compressing the spleen, and these findings were reported as pancreatitis, pancreatic pseudocyst, splenic hemorrhage with intracapsular and extracapsular components (Figure 1, 2).

The patient was emergently operated following resuscitation. At laparotomy, approximately $1500 \mathrm{cc}$. of hemorrhagic fluid was present in the abdomen, a splenic hematoma reaching about $12-13 \mathrm{~cm}$ in diameter, surrounding the spleen with hilar rupture and pancreatic necrosis on the anterior aspect were found. The patient underwent splenectomy and necrosectomy. She was discharged on the sixth postoperative day without any complications. 


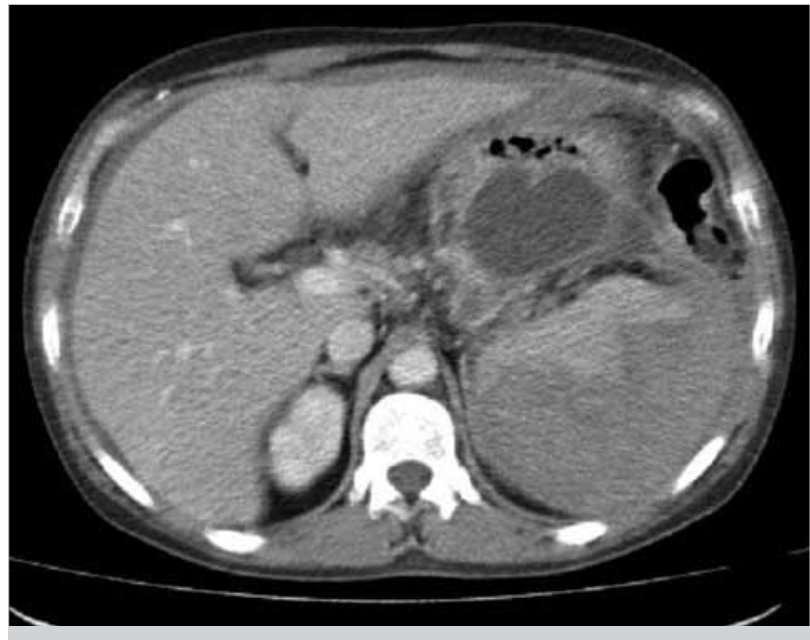

Figure 1. Splenic hematoma related to a pancreatic pseudocyst

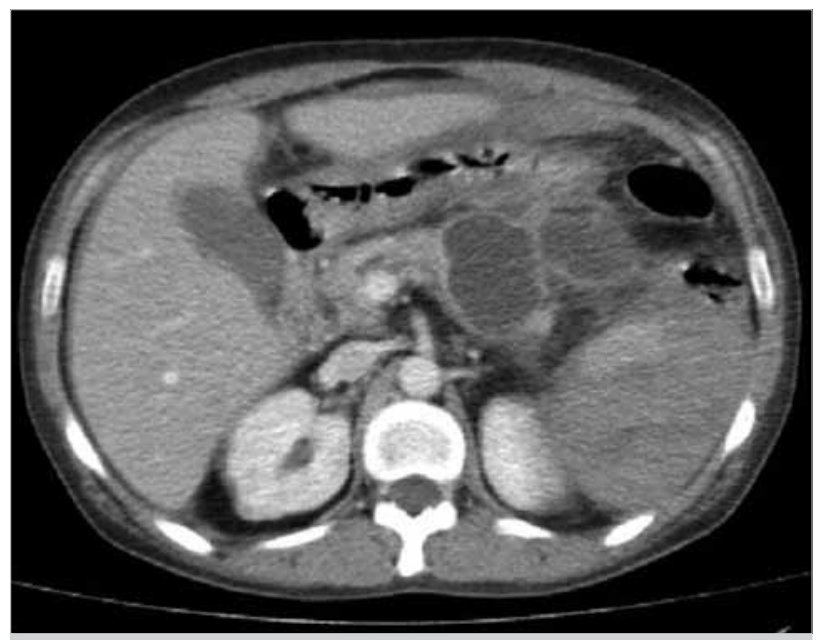

Figure 2. Intra- and extra-capsular splenic hemorrhage with pancreatitis, pancreatic pseudocyst

\section{DISCUSSION}

Splenic subcapsular hematoma and rupture is a rare complication of pancreatitis (2-4). Malka et al. (1) reported 11 patients (2.2\%) with splenic complications in their series of 500 pancreatitis cases, in two of these splenic hematoma (0.4\%) were identified and one case $(0.2 \%)$ required an emergency splenectomy, as in our case. Anatomically, the pancreatic tail, splenic hilum and splenic veins are in close proximity therefore, this complication may be expected in severe pancreatitis. Other possible splenic complications of pancreatitis are; splenic vein thrombosis, arterial pseudoaneurysm, intrasplenic pancreatic pseudocyst, abscess, splenic subcapsular infection, hematoma, necrosis, and splenic rupture and these complications can be seen at rates between $1-5 \%(1,5,6)$. Our patient with chronic pancreatitis presented with hemorrhagic shock, abdominal tenderness and elevation of amylase levels. The emergency abdominal CT has identified pancreatitis, pancreatic pseudocyst, subcapsular hematoma and rupture. Diagnosis of splenic complications is important in acute or chronic pancreatitis. For such a diagnosis, first this complication should be considered in patients with a history of pancreatitis, then splenic complications should be suspected in the presence of a left upper quadrant mass, pain radiating to the left shoulder, left pancre- atic pleural effusion, a decrease in hemoglobin values, splenic vein occlusion, distal pseudocyst and pancreatic tail necrosis following acute exacerbation (1). In patients with suspected splenic complications, an emergent abdominal CT should be performed immediately after the initial survey $(4,5,7)$.

Knowledge on the etiology of pancreatitis complications is necessary for the determination and follow-up of complications. Possible mechanisms of splenic complications in pancreatitis have been defined as; formation of thrombosis and pseudo-aneurysm in the splenic vein, dissection of pancreatic pseudocysts into the splenic hilum with splenic rupture, splenic infarction, arterial bleeding or venous thrombosis, progression of infectious process from the tail of the pancreas towards the splenic hilum and formation of hematoma $(1,6)$. In addition to these local factors, coagulation disorders may also be involved in the pathogenesis of splenic hematoma (8). In our patient there were no known coagulation disorders, and we believe that the pseudocyst, that was previously drained during a severe pancreatitis episode complicated with acute renal failure, most probably lead to the expansion of inflammation and erosion at the splenic hilum, resulting in a subcapsular hematoma.

The management of splenic subcapsular hematoma associated with pancreatitis is controversial. Observation, percutaneous drainage and surgical treatment are possible options. Arterial embolization that can be used both for diagnosis of etiology or treatment of bleeding should create a splenic infarction area less than $50 \%$ of the splenic volume. Its role is limited due to the facts that in the literature it is reported to be associated with splenic abscess in $25 \%$ of cases, with only a few numbers of published cases and lacking data on longterm results (9). In general, conservative approach is preferred for splenic pathologies as much as possible. Splenic complications associated with pancreatitis have been reported to spontaneously regress from 1 week to 4 months (7). Patel et al. (3) treated a patient with a giant subcapsular splenic hematoma, $11.1 \times 9.5 \mathrm{~cm}$ in dimensions, following pancreatitis conservatively and they reported significant resolution of the hematoma in the abdominal CT four months later, and have proposed conservative treatment in hemodynamically stable patients showing clinical improvement. A similar subcapsular splenic hematoma $(10 \times 10 \mathrm{~cm})$ that was followed up for 6 weeks did not change in diameter, and it ruptured during the next pancreatitis episode. The authors suggested that splenic hematomas larger than $5 \mathrm{~cm}$ following pancreatitis should be percutaneously drained or should be surgically intervened to reduce its pressure in patients without clinical improvement, and that the follow up period should not exceed 6 weeks (10). In our case any pathology of the spleen was not found and a splenic hematoma was encountered after a period of 4 months. Different from other known complications of the pancreas, the possible formation time of this complication and its treatment algorithm are not clear. We believe management of splenic subcapsular hematoma following pancreatitis with the same parameters as in traumatic or other splenic hematomas is not an appropriate method. As is seen in our case, the risk of splenic rupture should not be ignored before elimination of 
the etiology. There are case reports that document successful treatment of large splenic hematomas in patients with chronic pancreatitis by percutaneous drainage and thus preventing splenectomy $(2,6,11)$. Percutaneous drainage may be a viable treatment option for splenic subcapsular collections, however hemodynamic stability and infection parameters should be considered in patient selection. A more aggressive approach, early splenectomy, has also been advocated for the treatment of splenic hematoma in order to prevent blood loss and potential splenic rupture $(1,8,10)$. In addition, it is emphasized that waiting for the resolution of splenic hematoma is risky due to segmental portal hypertension present during the course of chronic pancreatitis (4).

\section{CONCLUSION}

Splenic complications associated with acute and chronic pancreatitis should be kept in mind in emergency practice, should be diagnosed early and followed up closely. The follow-up and treatment of splenic complications should not be similar to the follow-up and treatment of traumatic subcapsular hematoma, follow up criteria must be defined and keeping the next probable pancreatitis attack in mind radical treatment should be planned as soon as possible.

Informed Consent: Written informed consent was obtained from patients who participated in this case.

Peer-review: Externally peer-reviewed.

Author Contributions: Concept - F.C., S.Y., E.I.; Design - F.C., S.Y., E.I.; Data Collection and/or Processing - F.C., S.Y.; Analysis and/or Interpretation F.C., S.Y.; Writer - F.C.

Conflict of Interest: No conflict of interest was declared by the authors.
Financial Disclosure: The authors declared that this study has received no financial support.

\section{REFERENCES}

1. Malka D, Hammel P, Lévy P, Sauvanet A, Ruszniewski P, Belghiti J, et al. Splenic complications in chronic pancreatitis: prevalence and risk factors in a medical-surgical series of 500 patients. $\mathrm{Br} J$ Surg 1998; 85: 1645-1649. [CrossRef]

2. Kim Yl, Park SY, Lee JH, Kee WJ, Park CH, Kim HS, et al. A case of pancreatic pseudocyst with a large subcapsular splenic hematoma treated successfully by ultrasonography-guided percutaneous drainage. Korean J Gastroenterol 2011; 57: 258-261. [CrossRef]

3. Patel VG, Eltayeb OM, Zakaria M, Fortson JK, Weaver WL. Spontaneous subcapsular splenic hematoma: a rare complication of pancreatitis. Am Surg 2005; 71: 1066-1069.

4. Habib E, Elhadad A, Slama JL. [Diagnosis and treatment of spleen rupture during pancreatitis]. Gastroenterol Clin Biol 2000; 24: 1229-1232.

5. Gandhi V, Philip S, Maydeo A, Doctor N. Ruptured subcapsular giant haematoma of the spleen--a rare complication of acute pancreatitis. Trop Gastroenterol 2010; 31: 123-124.

6. Tseng CW, Chen CC, Chiang JH, Chang FY, Lin HC, Lee SD. Percutaneous drainage of large subcapsular hematoma of the spleen complicating acute pancreatitis. J Chin Med Assoc 2008; 71: 92-95. [CrossRef]

7. Rypens F, Devière J, Zalcman M, Braudé P, Van de Stadt J, Struyven J, et al. Splenic parenchymal complications of pancreatitis: CT findings and natural history. J Comput Assist Tomogr 1997; 21: 89-93. [CrossRef]

8. Thompson JE Jr, Ashley SW. Subcapsular hematoma of the spleen associated with acute pancreatitis. Surgery 1997; 121:231-233. [CrossRef]

9. Weber SM, Rikkers LF. Splenic vein thrombosis and gastrointestinal bleeding in chronic pancreatitis. World J Surg. 2003; 27: 1271-1274. [CrossRef]

10. Kuramitsu T, Komatsu M, Ono T, Nakajima K, Funaoka M, Kato J, et al. Ruptured subcapsular giant hematoma of the spleen as a complication of chronic pancreatitis. Intern Med 1995; 34: 564-568. [CrossRef]

11. Siu TL. Percutaneous drainage of spontaneous subcapsular haematoma of the spleen complicating chronic pancreatitis. Surgeon 2004; 2: 52-55. [CrossRef] 